
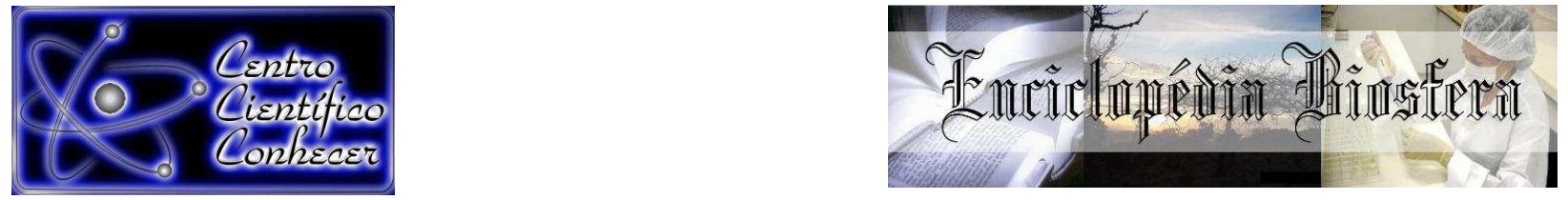

\title{
PARÂMETROS FÍSICO-QUÍMICOS DO MEL DE ABELHAS SEM FERRÃO DO ESTADO DO ACRE
}

Ludimila Klippel Aguiar $^{1}$, Delcio Dias Marques ${ }^{2}$, Rogerio Antonio Sartori ${ }^{3}$, Kennedy Lima da Silva ${ }^{4}$, Giulliano Cezarotto Scarante ${ }^{5}$

${ }^{1}$ Pós-graduanda, Universidade Federal do Acre, Rio Branco - Acre, Brasil ludmilaklippel2009@hotmail.com

${ }^{2}$ Doutor, Docente na Universidade Federal do Acre, Rio Branco - Acre, Brasil

${ }^{3}$ Doutor, Docente na Universidade Federal do Acre, Rio Branco - Acre, Brasil

${ }^{4}$ Pós-graduando, Universidade Federal do Acre, Rio Branco - Acre, Brasil

${ }^{5}$ Pós-graduando, Universidade Federal do Acre, Rio Branco - Acre, Brasil

Recebido em: 08/04/2016 - Aprovado em: 30/05/2016 - Publicado em: 20/06/2016 DOI: 10.18677/Enciclopedia_Biosfera_2016_078

Dentre as abelhas sociais, além das Apis mellifera, estão presentes as da tribo Meliponini com vários grupos de abelhas sem ferrão, que produzem mel. Apesar de importância ecológica e medicinal do mel das abelhas da tribo Meliponinae, não existe legislação específica para a sua caracterização. Neste sentido, foram determinados os parâmetros físico-químicos dos méis de três espécies de abelha Meliponinae: Tetragonisca weyrauchi (Schwarz,1943) (jati), coletada no campus da Universidade Federal do Acre, Tetragonisca angustula (Latreille, 1811) (jataí) e Trigona spinipes (Fabricius, 1793) (arapuá) coletadas no município de Acrelândia, Acre. As amostras foram submetidas às análises físico-químicas como: umidade (\%), acidez ( $\left.\mathrm{mEq} \mathrm{kg}{ }^{-1}\right)$, cinzas (\%), açúcares redutores (\%), potencial hidrogeniônico $(\mathrm{pH})$, condutividade elétrica $\left(\mathrm{mS} \mathrm{cm}^{-1}\right)$, sólidos solúveis totais (ํㅏix), cor (ABS), 5hidroximetilfurfural $\left(\mathrm{mg} \mathrm{kg}^{-1}\right)$ e atividade diastásica (Gothe). Três testes de controle de adulteração foram realizados: Lugol, Fiehe e Lund. A espécie jati foi à única que apresentou parâmetros físico-químicos dentro dos padrões estabelecidos pela legislação brasileira para mel de Apis mellifera. Os parâmetros físico-químicos de umidade (jataí $21,20 \%$, arapuá $20,60 \%$ ), cinzas (arapuá 0,93\%) acidez total (jataí $57,49 \mathrm{mEq} \mathrm{kg}{ }^{-1}$, arapuá $220,94 \mathrm{mEq} \mathrm{kg}^{-1}$ ) e açúcar redutor (jataí $77,30 \%$ ) não obedeceram à legislação vigente ficando acima dos valores descritos para o mel de Apis, reforçando a necessidade de uma normatização apropriada para os méis de abelhas sem ferrão. Os resultados das reações de identificação de adulterações indicaram que as amostras de mel não apresentaram indícios de alterações, portanto se tratando de mel puro.

PALAVRAS-CHAVE: Abelhas sem ferrão, mel, Parâmetros físico-químicos.

\section{PARAMETERS PHYSICAL AND CHEMICAL HONEY BEES STINGLESS ACRE STATE}

\section{ABSTRACT}

Among the social bees, in addition to Apis mellifera, are present those of Meliponini tribe with several groups of stingless bees that produce honey. Although there is very ENCICLOPÉDIA BIOSFERA, Centro Científico Conhecer - Goiânia, v.13 n.23; p. 9082016 
ecological and medicinal importance for the honeys from the Meliponinae bee tribe there is no specific legislation for their characterization. In this sense, the physicochemical parameters of the honeys from three species of bee Meliponinae were determined as it follows: Tetragonisca weyrauchi (Schwarz, 1943) (jati), collected in the Federal University of Acre campus, Tetragonisca angustula (Latreille, 1811) (jataí) e Trigona spinipes (Fabricius, 1793) (arapuá) both collected at the surroundings of Acrelândia, a city from Acre state. Samples were submitted for physico-chemical analyses such as: Humidity (\%), acidity $\left(\mathrm{mEq} \mathrm{kg}{ }^{-1}\right)$, ash content (\%), Reducing sugars (\%), $\mathrm{pH}$, electrical conductivity $\left(\mathrm{mS} \mathrm{cm}^{-1}\right)$, total soluble solids (Brix), color (absorbance), hydroxymethylfurfural ( $\mathrm{mg} \mathrm{kg}^{-1}$ ) and diastase activity (Gothe). Three adulteration tests were performed as controls: Lugol, Fiehe e Lund.

The jati specie has been the only one that shows physicochemical parameters that attends the standard values established by the Brazilian legislation for honeys of Apis mellifera. Physicochemical properties such as humidity (jataí $21.20 \%$, arapuá $20.60 \%$ ), ash content (arapuá 0.93\%), total acidity (jataí $57.49 \mathrm{mEq} \mathrm{kg-1}$, arapuá $220.94 \mathrm{mEq} \mathrm{kg-1}$ ) and reducing sugar (jataí 77.30\%) did not follow the current Brazilian regulations for Apis honeys, having higher values than those established by legislation, reinforcing the need of an appropriate normalization for the honeys of stingless bees. The reaction tests confirmed that there is no evidence of adulteration, being considered the samples as pure honey.

KEYWORDS: Honey, Bees stingless, Physical-chemical parameters.

\section{INTRODUÇÃO}

A criação de abelhas no Brasil representa uma importante fonte de renda complementar, para muitas famílias de pequenos e médios produtores rurais. $O$ Brasil apresenta um grande potencial para a prática da apicultura em função de sua vasta biodiversidade da flora Brasileira com seus vários biomas, onde apresentam uma alta diversidade de espécies vegetais. Outro fator importante está relacionado com a sua ampla extensão territorial e, por último, o seu clima tropical e temperado favorável a exploração da apicultura, permitindo desta forma a produção de mel de diversas floras, durante todo o ano (ALMEIDA-FILHO et al., 2011). Após a década de 1970, iniciou no Brasil um desenvolvimento e implantação de técnicas adequadas de manejo e produção de mel de abelha do gênero Apis, levando a atividade de apicultura ser praticado em todo território nacional (QUEIROGA et al., 2015). Conforme IBGE (2013), a safra de mel alcançou a cifra de 35 mil toneladas, um aumento de 4,2\%, em relação ao ano anterior, sendo assim definida em 2013: Sul $(50,2 \%)$, Sudeste $(21,5 \%)$, Nordeste $(21,3 \%)$, Centro-Oeste $(4,4 \%)$ e Norte $(2,6 \%)$. Apesar da baixa produção de mel nas regiões Centro-Oeste e Norte, o estado de Goiás registrou entre 1998 a 2013 um aumento na produção de 308\%, com 344 toneladas e o estado do Acre com 8 toneladas em 2013 (IBGE, 2013; ARAUJO et al., 2015).

Conforme instrução normativa do Ministério de Agricultura e Abastecimento - mel foi definido como o "produto alimentício produzido pelas abelhas Apis mellifera, a partir do néctar das flores ou das secreções procedentes de partes vivas das plantas ou de excreções de insetos sugadores de plantas que ficam sobre partes vivas de plantas, que as abelhas recolhem, transformam, combinam com substâncias específicas próprias, armazenam e deixam madurar nos favos da colméia" (BRASIL, 2000). Apesar de a normativa restringir o mel como produto das abelhas melíferas, o mundo das abelhas é muito vasto e complexo. Além das 
abelhas solitárias, como as mangangavas (Xylocopa spp.), que visitam as plantações de maracujá, com o papel fundamental na polinização dessa produção agrícola, existem as abelhas sociais, entre elas as da tribo Meliponini, que foram as grandes produtoras de mel antes de introdução das espécies Apis mellifera no Brasil, com importante papel por apresentar produtos e subprodutos valorizados economicamente (SILVA \& PAZ, 2012).

Os meliponineos têm um papel fundamental, por ser um dos principais polinizadores, sendo os responsáveis pela manutenção e perpetuação de muitas espécies nativas nas florestas Brasileiras (SILVA \& PAZ, 2012). As Meliponas são abelhas que tem uma característica peculiar, pois apresentam o ferrão atrofiado, de onde vem o nome: abelhas sem ferrão. Essas espécies estão distribuídas nas regiões tropicais e subtropicais do globo terrestre. As abelhas da espécie Tetragonisca angustula (Latreille, 1811) conhecidas como "jataí", são encontradas desde o México até o Rio Grande do Sul e as Trigona spinipes (Fabricius, 1793), também conhecidas como "arapuá", ocorrem desde o Ceará até o Rio Grande do Sul, no Paraguai e na Argentina (PRONI \& MACIEIRA, 2004).

O mel é considerado uma solução concentrada de açúcares (75\%), com predominância dos monossacarídeos, como a glicose e frutose e pequenas quantidades de dissacarídeos, como a sacarose e maltose; água (20\%) e minerais como cobre, magnésio, cálcio e potássio, (ALQARNI et al., 2014; DAMASIA-GOMES et al., 2015). Conforme KAMAL \& KLEIN (2011), a concentração de água varia de 17 a $20 \%$ e os açúcares frutose, sacarose e glicose caracterizam a doçura do mel, sendo determinante a concentração da frutose, por apresentar poder adoçante superior aos demais açúcares. A composição química do mel, além dos carboidratos, também é constituída de outras substâncias como ácidos, sais minerais, proteínas, vitaminas, alcoóis, pigmentos e colóides, originando um produto bastante diversificado quanto a sua cor sabor e aroma. Essas características dependem fundamentalmente da origem do néctar, das condições climáticas e geográficas (ESCUREDO et al., 2014, SILVA et al., 2016).

O Brasil e os países membros do Mercosul estão com o objetivo de estabelecer normas segundo as diretrizes da Codex Alimentarium, para o mel de origem de abelhas sem ferrão (CHUTTONG et al., 2016). Neste contexto, a realização de pesquisa na caracterização dos parâmetros físico-químicos de mel das abelhas sem ferrão torna-se necessário e, para tanto, o presente trabalho tem como objetivo determinar as características físico-químicas do mel de Tetragonisca angustula (jataí), Tetragonisca weyrauchi (Schwarz,1943) (jati) e Trigona spinipes (arapuá) obtidos no Estado do Acre, visando contribuir para o estabelecimento de um padrão de qualidade do mel produzido pelas abelhas sem ferrão.

\section{MATERIAL E MÉTODOS}

As amostras de mel das espécies de abelhas sem ferrão, Trigona spinipes (arapuá) (323g) e Tetragonisca angustula (jataí) (241g) foram coletadas diretamente da colônia, na área rural do município Acrelândia, com predominância de vegetação nativa, do Estado Acre, Brasil, e a Tetragonisca weyrauchi (jati) (178g) coletada no campus da Universidade Federal do Acre (UFAC). As amostras coletadas foram enviadas ao Laboratório de Química da UFAC, sendo as espécies identificadas por entomólogo e tombadas com os registros RAS-001, LKA-002 e DDM-003, respectivamente, sendo arquivadas na coleção de abelhas do Laboratório de Ecologia e Insetos da UFAC. 
Os parâmetros analisados foram: teor de umidade (\%), teor de sólidos solúveis totais ( ${ }^{\circ}$ Brix), teor de resíduo mineral fixo ou cinzas (\%), potencial hidrogênionico $(\mathrm{pH})$, acidez livre, lactônica e total (meq $\left.\mathrm{kg}^{-1}\right)$, açúcar $(\%)$, atividade diastásica (Gothe), cor (ABS), condutividade elétrica $\left(\mathrm{mS} \mathrm{cm}^{-1}\right)$, 5-hidroximetilfurfural $\left(\mathrm{mg} \mathrm{kg}^{-1}\right)$ e três testes de controle de adulterantes: Lund, Lugol e Fiehe. As análises foram determinadas em triplicatas, exceto os testes de Lugol e Fiehe.

Teor de umidade (\%)

Determinado pelo método refratométrico conforme metodologia estabelecida pelo Instituto Adolfo Lutz (2008), utilizando refratômetro Abbé, modelo NI WYA-2S.

\section{Teor de Sólidos Solúveis Totais ( ${ }^{\circ}$ Brix)}

Determinado pelo método refratométrico conforme metodologia estabelecida pelo Instituto Adolfo Lutz (2008), utilizando refratômetro Abbé, modelo NI WYA-2S.

Teor de Cinzas (\%)

Determinado por incineração de $5 \mathrm{~g}$ de amostra em mufla a $550^{\circ} \mathrm{C}$, sendo inicialmente carbonizada em chama, conforme técnica estabelecida pelo INSTITUTO ADOLFO LUTZ (2008), utilizando mufla Fornitec, modelo 1615.

\section{Potencial hidrogênionico $(p H)$}

Determinado pelo método potenciométrico, usando $10 \mathrm{~g}$ da amostra de mel diluída em $100 \mathrm{~mL}$ de água destilada. $\mathrm{O} \mathrm{pH}$ foi determinado com o auxílio de um $\mathrm{pH}$ metro QUIMIS, modelo Mlcronal, previamente calibrado (IAL, 2008).

\section{Acidez livre, Lactônica e Total ( $\left.\mathrm{mEq} \mathrm{kg}{ }^{-1}\right)$}

Determinados pelo método potenciométrico usando $10 \mathrm{~g}$ da amostra dissolvida em $75 \mathrm{~mL}$ de água. A solução foi titulada com hidróxido de sódio 0,05 $\mathrm{M}$ até $\mathrm{pH} 8,5(\mathrm{Va})$, volume usado para o cálculo de acidez livre. Imediatamente, foi adicionado $10 \mathrm{~mL}$ de solução de hidróxido de sódio $0,05 \mathrm{M}$ e titulado com ácido clorídrico 0,05 $\mathrm{M}$ até o $\mathrm{pH} 8,30(\mathrm{Vb})$, volume usado para cálculo da acidez lactônica. Acidez total representa a soma de acidez livre mais acidez lactônica. Foi utilizado ph-metro, QUIMIS, modelo Micronal, previamente calibrado (IAL, 2008).

\section{Açúcares Redutores}

Determinados de acordo com a metodologia do Instituto Adolfo Lutz (2008). Foi preparada uma solução $2 \mathrm{~g}$ da amostra em balão volumétrico de $200 \mathrm{~mL}$. Uma alíquota de $50 \mathrm{~mL}$ foi diluída quantitativamente a $100 \mathrm{~mL}$, usada como solução titulante. Adicionou-se $5 \mathrm{~mL}$ de cada solução A e B de Fehling para um balão de fundo chato de $250 \mathrm{~mL}$, contendo $7 \mathrm{~mL}$ de água. Usando bureta de $25 \mathrm{~mL}$ com a solução titulante, foram adicionados $15 \mathrm{~mL}$ no balão de fundo chato, levando a ebulição moderada. Em seguida, adicionou-se $1 \mathrm{~mL}$ da solução de azul de metileno (1\%), ainda em ebulição e finalizada a titulação até a descoloração do indicador.

\section{Atividade diastásica (Gothe)}

Determinada usando $5 \mathrm{~g}$ de amostra de mel diluído com $10 \mathrm{~mL}$ de água destilada e 2,5 $\mathrm{mL}$ do tampão de acetado $(1,59 \mathrm{M}, \mathrm{pH}=5,3)$. A solução foi transferida para um balão volumétrico de $25 \mathrm{~mL}$ contendo $1,5 \mathrm{~mL}$ de $\mathrm{NaCl}$ a $0,5 \mathrm{M}$, e completado o volume. $10 \mathrm{~mL}$ foram incubados em banho termostático à $40^{\circ} \mathrm{C}$ 
juntamente com a solução de amido a $1 \%(\mathrm{~m} / \mathrm{v})$, por 5 minutos. Logo após, foi retirado $5 \mathrm{~mL}$ da solução de amido e adicionado a solução de mel, permanecendo no banho por mais 5 minutos. Depois de decorrido o tempo, foi retirado $1 \mathrm{~mL} e$ rapidamente adicionado a $10 \mathrm{~mL}$ de solução de iodo a $0,0007 \mathrm{M}$. A absorbância foi medida a $660 \mathrm{~nm}$, em intervalo de 5 minutos, usando espectrofotômetro UV-VIS da SHUMADZU, modelo SP-220. Um gráfico de absorbância versus tempo foi registrado até obter valor menor que 0,235 (CHUTTONG et al., 2016). O cálculo foi realizado segundo Instituto Adolfo Lutz (2008).

\section{$\operatorname{Cor}(A B S)$}

A cor foi verificada conforme método de Bianchi (LACERDA et al., 2010) que consiste na medida da absorbância a $635 \mathrm{~nm}$ de uma solução aquosa $50 \%(\mathrm{~m} / \mathrm{v})$ do mel. A solução foi deixada em repouso por 15 minutos e determinada a absorbância em espectrofotômetro UV-VIS, SHUMADZU, modelo SP-220. A classificação foi dada pela escala de Pfund.

Condutividade elétrica $\left(\mathrm{mS} \mathrm{cm}^{-1}\right)$

Medida em solução aquosa de mel a $20 \%$, utilizando condutivímetro HANNA, modelo HI8820, Digimed (SOHAIMY et al., 2015).

\section{5-Hidroximetilfurfural $\left(\mathrm{mg} \mathrm{kg}^{-1}\right)$}

O índice de 5-HMF foi determinado de acordo com o INSTITUTO ADOLFO LUTZ (2008). $5 \mathrm{~g}$ da amostra foram diluídos com $25 \mathrm{~mL}$ de água em balão volumétrico de $50 \mathrm{~mL}$. Foi adicionado $0,5 \mathrm{~mL}$ de cada solução, Carrez I e II e completando o volume com água. A solução foi filtrada desprezando os primeiros 10 $\mathrm{mL}$. Alíquotas de $5 \mathrm{~mL}$ foram adicionadas em tubos de ensaio com $5 \mathrm{~mL}$ de água. $\mathrm{O}$ branco foi determinado com $5 \mathrm{~mL}$ da solução de bissulfito de sódio $0,2 \%$ em $5 \mathrm{~mL}$ de água. A absorbância foi determinada a 284 e $336 \mathrm{~nm}$.

\section{Teste de Lund}

O teste de Lund foi realizado com $2 \mathrm{~g}$ da amostra diluída em $20 \mathrm{~mL}$ de água, em uma proveta de $50 \mathrm{~mL}$, com tampa. Foi adicionado $5 \mathrm{~mL}$ de solução de ácido tânico $0,5 \%$ e água até completar o volume de $40 \mathrm{~mL}$. Após 24 horas em repouso foi observada a presença de precipitado na proveta no intervalo de 0,6 a 3,0 mL (IAL, 2008).

Teste de Lugol

O teste foi realizado com $10 \mathrm{~g}$ de amostra diluído com $20 \mathrm{~mL}$ de água em um béquer. Em banho-maria foi aquecido por uma hora e após resfriado a temperatura ambiente, foi adicionado $0,5 \mathrm{~mL}$ da solução de Lugol (IAL, 2008).

\section{Teste de Fiehe}

Foi realizado com $5 \mathrm{~g}$ de amostra dissolvido em $5 \mathrm{~mL}$ de éter etílico. A fase orgânica foi transferida para um tubo de ensaio e adicionada $0,5 \mathrm{~mL}$ de solução clorídrica de resorcina 5\%, deixando em repouso por 10 minutos (IAL, 2008). 


\section{RESULTADOS E DISCUSSÕES}

A Tabela 1 apresenta os valores médios dos parâmetros físico-químicos e desvio padrão (DP) do mel das espécies Tetragonisca angustula (jataí), Trigona spinipes (arapuá) e Tetragonisca weyrauchi (jati).

TABELA 1- Valores médios dos parâmetros físico-químicos e desvio padrão (DP) do mel de abelhas, jataí, arapuá e jati.

\begin{tabular}{l|c|c|c}
\hline \multirow{2}{*}{ Parâmetros } & \multicolumn{3}{|c}{ Amostras / DP } \\
\cline { 2 - 4 } & $\begin{array}{c}\text { Tetragonisca } \\
\text { angustula }\end{array}$ & $\begin{array}{c}\text { Trigona } \\
\text { spinipes }\end{array}$ & $\begin{array}{c}\text { Tetragonisca } \\
\text { weyrauchi }\end{array}$ \\
\hline Umidade (\%) & $21,20 \pm 0,11$ & $20,60 \pm 0,13$ & $19,80 \pm 0,13$ \\
\hline $\mathrm{pH}$ & $4,13 \pm 0,3$ & $2,98 \pm 0,01$ & $4,63 \pm 0,01$ \\
\hline Cinzas (\%) & $0,48 \pm 0,11$ & $0,93 \pm 0,04$ & $0,32 \pm 0,04$ \\
\hline Acidez Livre (mEq kg $\left.{ }^{-1}\right)$ & $66,96 \pm 0,12$ & $219,47 \pm 0,15$ & $43,37 \pm 0,18$ \\
\hline Acidez Latônica $\left(\mathrm{mEq} \mathrm{kg}^{-1}\right)$ & $0,53 \pm 0,13$ & $1,49 \pm 0,16$ & $0,25 \pm 0,18$ \\
\hline Acidez Total (mEq kg $\left.{ }^{-1}\right)$ & $67,49 \pm 0,13$ & $220,94 \pm 0,16$ & $43,37 \pm 0,18$ \\
\hline Sólidos Solúveis Totais ('Brix) & $77,60 \pm 0,11$ & $66,70 \pm 0,13$ & $73,51 \pm 0,13$ \\
\hline Cor (ABS) & $1,122 \pm 0,04$ & $1,498 \pm 0,01$ & $1,021 \pm 0,01$ \\
\hline 5-Hidroximetilfurfural (mg kg-1) & $21,52 \pm 0,37$ & $24,73 \pm 0,19$ & $19,59 \pm 0,65$ \\
\hline Açúcares Redutores (\%) & $77,30 \pm 0,13$ & $57,70 \pm 1,07$ & $70,32 \pm 0,19$ \\
\hline Atividade Diastásica (Gothe) & $12,5 \pm 0,084$ & $15,0 \pm 0,027$ & $12,5 \pm 0,014$ \\
\hline Condutividade Elétrica (mS cm $\left.{ }^{-1}\right)$ & $0,725 \pm 0,87$ & $0,587 \pm 0,64$ & $0,683 \pm 0,91$ \\
\hline Teste de Lugol & Negativo & Negativo & Negativo \\
\hline Teste de Lund & $1,6 \pm 0,24$ & $2,2 \pm 0,24$ & $1,2 \pm 0,14$ \\
\hline Teste de Fiehe & Negativo & Negativo & Negativo \\
\hline
\end{tabular}

O teor médio de umidade do mel variou de $19,80( \pm 0,13)$ a $21,20( \pm 0,11)$ conforme apresentado na Tabela 1. Este parâmetro representa na composição centesimal do mel o segundo componente em maior concentração, e conforme ALMEIDA-FILHO et al., (2011) pode variar de $15 \%$ a $21 \%$, diferentemente dos valores mencionados por KAMAL \& KLEIN (2011), que caracterizou a concentração de água variando de $17 \%$ a $20 \%$. Embora os valores das espécies $T$. angustula (jataí) $21,20( \pm 0,11)$ e $T$. spinipes (arapuá) 20,60 $( \pm 0,13)$ estejam um pouco acima do regulamentado pela legislação brasileira, que estabeleceu o valor máximo de $20 \%$ (BRASIL, 2000), os valores estão dentro da faixa para o mel das abelhas sem ferrão, em conformidade com os obtidos por SOUZA et al., (2004), estudando várias espécies de abelhas sem ferrão encontrou média de $28,6 \%( \pm 4,6)$. Outra pesquisa realizada por CHUTTONG et al., (2016) estudando o mel de várias espécies de abelhas sem ferrão, da região da Tailândia, encontrou valor médio de $31,0 \%( \pm 5,4)$, tendo a espécie Tetrigona apicalis registrado valor de 47,37\%, com o maior teor de umidade. DAMASIA-GOMES et al. (2015) analisando as características físicoquímicas do mel do Brasil observou que o teor da umidade para o mel de abelhas sem ferrão variou de $23,79 \%$ a $28,78 \%$, respectivamente para Melipona fasciulata e M. mandacaia. Os autores relataram que naturalmente a umidade dos méis de abelhas sem ferrão encontra-se acima do estabelecido pela legislação brasileira para méis da Apis mellifera, reforçando a necessidade de estabelecimento de 
normas para o grupo de abelhas sem ferrão.

A umidade é um fator bastante afetado pelo clima, como também outras propriedades do mel, sejam de abelhas Apis ou abelhas sem ferrão. Como o clima tropical da floresta Amazônica conserva uma alta umidade relativa do ar, pode interferir no conteúdo de água do mel, elevando a sua concentração. No entanto, alta concentração de água no mel, aumenta a probabilidade de desenvolvimento de leveduras osmofílicas, levando a degradação precoce do mel, além de promover doenças por microorganismos, podendo ser, portanto, um parâmetro para a caracterização de prazo de validade do mel (CHAVES et al., 2012).

A legislação brasileira não faz menção ao teor de $\mathrm{pH}$, entretanto as amostras analisadas de mel das abelhas apresentaram relativamente acida variando de 2,98 $( \pm 0,01)$ para o mel de Trigona spinipes a 4,63 $( \pm 0,01)$ para Tetragonisca weyrauchi, valores semelhantes ao encontrados por LACERDA et al., (2010) que registraram valores variando de 3,64 a 5,4, obtidos de amostras de mel da Apis mellifera do estado da Bahia. Em comparação com o potencial hidrogeniônico do mel brasileiro de origem de abelhas sem ferrão, que registrou valor de 3,27 a 4,66, respectivamente para o mel de Melipona mandacaia e $M$. scutllaris, apenas o mel de Trigona spinipes registrou valor inferior $(2,98 \pm 0,01)$ e as demais se encontraram dentro do intervalo de $\mathrm{pH}$ registrou para o mel de abelhas sem ferrão produzido no Brasil (DAMASIA-GOMES et al., 2015).

O mel é um produto considerado de acidez moderada e está relacionada com a origem botânica do néctar e pelas condições do pH do solo (MOURA et al., 2014). Os estudos realizados por SOHAIMY et al., (2015) com amostras de mel de diferentes regiões do Oriente, registraram valores de $\mathrm{pH}$ que variaram de 4,11 $( \pm 0,02)$ a $4,63( \pm 0,03)$ para as amostras analisadas. Segundo os autores, o alto teor no $\mathrm{pH}$ pode ser justificado em função da oxidação dos açúcares originando ácidos orgânicos e também pode está correlacionado com o teor de minerais. Neste sentido, o mel de $T$. spinipes (arapuá) analisado nesta pesquisa apresentou $\mathrm{pH} \mathrm{4,45}$ $( \pm 0,01)$, o que pode ser justificado em função do alto teor de minerais $0,93( \pm 0,04)$.

Os teores de cinzas encontrados nas amostras estudadas variaram entre 0,48 $( \pm 0,11)$ a $0,93( \pm 0,04)$. Apenas a amostra do mel de T.spinipes (arapuá) registrou valor acima do estabelecido pela legislação brasileira que estabeleceu o máximo de 0,60\% (BRASIL, 2000). Entretanto, os valores encontrados neste estudo, estão em conformidade com os registrados por CHUTTONG et al. (2016), que observou média de 0,531 ( \pm 0.632$)$. O teor de cinzas representa a concentração de sais minerais e está relacionada com a coloração do mel. Neste sentido, existe uma correlação positiva entre a concentração de cinzas do mel de $T$. spinipes (arapuá), que registrou o maior teor de cinzas $0,93( \pm 0,04)$ e sua coloração mais intensa, absorbância de $1,498( \pm 0,16)$.

Os resultados obtidos para acidez livre em mEq kg ${ }^{-1}$ variou de $43,37( \pm 0,18)$ a $219,47( \pm 0,15)$ e para a acidez lactônica de $0,25( \pm 0,18)$ a $1,49( \pm 0,16)$ (Tabela 1$)$. Estes parâmetros não são exigidos pela legislação brasileira e, neste sentido, a exigência para o controle de qualidade se refere ao parâmetro de acidez total, com limite máximo de $50 \mathrm{mEq} \mathrm{Kg}{ }^{-1}$ (BRASIL, 2000). A acidez total das amostras de méis analisadas, apenas a espécie $T$. weyrauchi (jati) apresentou valor dentro da legislação brasileira (BRASIL, 2000), com teor de 43,37 $( \pm 0,18)$. O valor registrado para a Trigona spinipes $220,94( \pm 0,16)$, foi muito superior ao encontrado para o mel de abelhas sem ferrão do Brasil, que variou de $31,88( \pm 7,10)$ para o mel de Melipona fasciulata a 98,43 $( \pm 5,51)$ para Scaptotrigona depilis (DAMASIA-GOMES et al., 
2015). A acidez do mel, assim como o teor de umidade, representa um importante componente que contribui com o controle no desenvolvimento de microorganismo. Este parâmetro está relacionado com a variação de ácidos orgânicos, que compõem a constituição química do néctar coletado pelas abelhas e, também com a função da enzima glicose-oxidase, que pode atuar oxidando a glicose originando ácido glucônico (ALMEIDA-FILHO et al., 2011). Outro fator que contribui, está relacionado com a concentração de minerais, principalmente com relação à presença de potássio e cálcio (PONTARA et al., 2012).

As amostras que apresentaram os maiores teores de cinzas foram do mel de $T$. angustula (jataí) com $0,48( \pm 0,11)$ e $T$. spinipes (arapuá) com $0,93( \pm 0,04)$ estabelecendo uma correlação positiva com a alta acidez total $67,49( \pm 0,13)$ e $220,94( \pm 0,16)$, respectivamente. Apesar desta alta acidez, os valores estão de conformidade com os resultados encontrados por CHUTTONG et al. (2016), que registraram valores variando de 25 a $592 \mathrm{mEq} \mathrm{kg}^{-1}$ para mel de abelhas sem ferrão, sendo a espécie Tetrigona melanoleuca com $592 \mathrm{mEq} \mathrm{kg}{ }^{-1}$, o maior valor registrado pelos autores. Exceto a amostra do mel da $T$. spinipes (arapuá), os demais resultados também estão de conformidade com os obtidos por ANACLETO et al. (2009), com amostra de mel de 28 colônias de abelha Tetragonisca angustula, que registraram valores variando de 17 a $98 \mathrm{mEq} \mathrm{kg}^{-1}$ de acidez.

Os sólidos solúveis totais, determinados em graus Brix, apresentaram valores variando com o mínimo de $22,70( \pm 0,13)$ para a espécie arapuá e máximo de 23,15 $( \pm 0,13)$ para jati.

A cor representa uma propriedade organoléptica que mais influência o consumidor, que normalmente escolhe o produto pela aparência. Este parâmetro está relacionado com a florada e nas amostras analisadas foram classificados como âmbar escuro, conforme a escala de Pfund (absorbância > 0,945). O mel de origem de florada silvestre normalmente origina coloração mais intensa, como no caso do mel de Trigona spinipes (arapuá), que mostrou absorbância de 1,498 $( \pm 0,01)$, revelando coloração mais escura, corroborando com o maior teor de cinzas (MOURA, et al., 2015). Conforme SOHAIMY et al., (2015) alta intensidade de absorbância indica presença de compostos fenólicos e flavonoides.

O teor de 5-hidroximetilfurfural medido em $\mathrm{mg} \mathrm{kg}^{-1}$ variou com o mínimo de $19,59( \pm 0,65)$ e máximo de $24,73( \pm 0,19)$, estando dentro das normas brasileiras que estabeleceu o máximo de $60 \mathrm{mg} \mathrm{kg}^{-1}$ (BRASIL, 2000). Este metabólito é um produto formado da reação de Maillard que pode ser catalisada pela presença de ácido ou quando o mel é submetido a tratamento térmico (SILVA et al., 2016). Outros fatores que pode também contribuir para a formação de 5-HMF, é a elevada temperatura de armazenamento, adição de adulterante de açúcares ou água (ALMEIDA-FILHO, et al., 2011).

Os valores encontrados para os açúcares redutores variaram na ordem de $57,70 \%( \pm 1,07)$ a $77,30 \%( \pm 0,13)$. Estes percentuais de glicídios estão acima dos valores encontrados por ANACLETO et al., (2009) que registraram valores entre $50,63 \%$ a $59,60 \%$, para a espécie Tetragonisca angustula. Valor semelhante foi obtido neste trabalho para a espécie Trigona spinipes (arapuá) que apresentou o valor mais baixo $57,70 \%( \pm 1,07)$, enquanto as espécies Tetragonisca angustula (jataí) e T. weyrauchi (jati) apresentaram valores de $77,30 \%( \pm 0,13)$ e $70,32 \%$ $( \pm 0,19)$, respectivamente, em conformidade com os resultados obtidos por SOUZA et al., (2004), estudando o mel de meliponineos da região Amazônica, que registraram valores variando de $67,2 \%$ a $75,5 \%$. As normas para o mel de Apis mellifera 
estabeleceu valor para açúcar redutor em sacarose de no máximo de 72\% (BRASIL, 200). Neste aspecto, a mel da Tetragonisca angustula registrou valor acima do teor máximo da morna vigente para o mel de Apis mellifera, como também dos observados por DAMASIA-GOMES et al. (2015) para méis de abelha sem ferrão de origem brasileira.

As enzimas presentes no mel desempenham importante papel na sua produção e no controle de qualidade. A diastase, enzima que degrada o amido presente nas glândulas das abelhas, é extremamente sensível ao calor, e a quantificação de sua atuação enzimática é denominada de atividade diastásica, determinada em escala Gothe. Este parâmetro é utilizado como controle de qualidade do mel, pois fornece informações sobre o grau de conservação e aquecimento do produto. As análises realizadas apresentaram valores que variaram de $12,5( \pm 0,084)$ a $15,0( \pm 0,027)$ na escala de Gothe, estando muito abaixo do estabelecido pela legislação brasileira, mínimo de 8 na escala de Gothe (BRASIL, 2000). A espécie Tetragonisca angustula apresentou índice de $12,5( \pm 0,084)$ Gothe, mesmo valor registrado para a espécie $T$. weyrauchi. Estes parâmetros se encontram em conformidade com os registrados por ANACLETO et al., (2009) que observou valores variando de 7,16 a 54,11. Os autores, em conformidade com VILLAS-BÔAS \& MALASPINA (2005), sugeriram o valor mínimo de 3,0, na escala Gothe, para a atividade diastásica, para o mel de abelhas sem ferrão de origem brasileira.

A condutividade elétrica, fundamentado no fato de que soluções constituídas de compostos iônicos conduzem corrente elétricas, não consta nas normas vigentes nacional. Representa um parâmetro relacionado diretamente com o valor de cinzas, entretanto outras propriedades físico-químicos como pH e teor de proteínas também estão relacionados com a condutividade elétrica. Os resultados sobre a condutividade elétrica variaram de 0,587 $( \pm 0,64)$ a $0,725( \pm 0,87) \mathrm{mS} \mathrm{cm}^{-1}$. Para este parâmetro não existe referência nas normas vigentes brasileira (BRASIL, 2000), entretanto, os índices registrados são inferiores aos obtidos por ANACLETO et al., (2009) que observaram teores variando de 1061 a $2700 \mu \mathrm{S} \mathrm{cm}{ }^{-1}$. Conforme os autores não existem sugestão para este parâmetro para o mel de abelhas sem ferrão.

As amostras dos méis das espécies de abelhas sem ferrão foram submetidas à pesquisa de presença de amido e dextrinas com a realização do teste de Lugol. A presença desses constituintes no mel levaria a formação de coloração marromavermelhada, indicando adulteração do produto, os resultados mostraram ausência de contaminantes de amido. Foi também analisado a presença de albuminóides, cuja ausência caracteriza méis adulterados, com a realização do teste de Lund. $O$ resultado do ensaio revelou um precipitado que variou na ordem de $1,2( \pm 0,14)$ a 2,2 $\mathrm{mL}( \pm 0,24)$, mostrando a presença de albuminóides nas amostras. $O$ resultado da análise mostrou que não houve adição de substâncias protéicas nos méis analisados e nem perda durante o processamento do produto. Por último, foi também realizado o teste de Fiehe que detecta fraude por adição de sacarose, apresentando resultado negativo. Os três ensaios qualitativos realizados: Lugol, Lund e Fiehe, indicaram se tratar de mel puro. Apesar da Legislação brasileira não fazer menção para estes ensaios, estes se mostram de grande importância para o controle de qualidade do mel, pois indica uma aplicação de técnicas adequadas, desde o processo de extração do mel até o armazenamento, na verificação de possíveis adulterações. 


\section{CONCLUSÃO}

Os resultados obtidos para os méis das três espécies de abelhas sem ferrão do estado do Acre, apenas o mel da jati mostrou-se dentro dos parâmetros da legislação brasileira para 0 mel da Apis mellifera. Quando comparado com a proposta de legislação de méis de meliponíneos, o mel de arapuá não se enquadra para os parâmetros de cinzas $(0,93 \% \pm 0,04)$ e acidez total $\left(220,94 \mathrm{mEq} \mathrm{kg}^{-1} \pm 0,16\right)$, pois estes valores estão acima dos teores da proposta para mel de abelhas sem ferrão.

Com relação à pureza do material estudado o mel foi considerado puro tendo em vista os três testes de identificação de possíveis adulterações ter revelado resultados negativos.

\section{AGRADECIMENTOS}

Ao Prof. Dr. Elder Ferreira Morato, entomólogo da Universidade Federal do Acre, pela identificação das espécies estudadas e a CAPES pela bolsa de mestrado concedida à primeira autora.

\section{REFERÊNCIAS}

ALMEIDA-FILHO, J. P.; MACHADO, A. V.; ALVES, F. M. S.; QUEIROGA, K. H.; CÂNDIDO, A. F. M. Estudo físico-químico de qualidade do mel de abelha comercializado no município de Pombal - PB. Revista Verde, v. 6, n. 3, p. 83-90, $2011 . \quad$ Disponível em: <http://www.gvaa.org.br/revista/index.php/RVADS/article/viewFile/738/655>. Acesso em: 22 jan. 2016.

ALQARNI, A. S.; OWAYSS, A. A.; MAHMOUD, A. A.; HANNAN, M. A. Mineral content and physical properties of local and imported honeys in Saudi Arabia. Journal of Saudi Chemical Society, v. 18, p. 618-625, 2014. DOI: <http://dx.doi.org/10.1016/j.jscs.2012.11.0091319-6103>. Acesso em: 05 dez. 2015.

ANACLETO, D.; SOUZA, B. A.; MARCHINI, L. C.; MORETI, A. C. C. C. Composição de amostras de mel de abelha Jataí (Tetragonisca angustula latreille, 1811). Ciência e Tecnologia de Alimentos, v. 29, n. 3, p. 535-541, 2009. Disponível em: <http://www.scielo.br/pdf/cta/v29n3/a13v29n3.pdf>. Acesso em: 12 fev. 2016.

ARAÚJO, F. D.; SILVA-NETO, C. M.; RIBEIRO, A. C. C.; OLIVEIRA, G. M.; NASCIMENTO, A. R. honey economic valuation in the state of Goiás: conservation and income. Agrarian Academy, v. 2, n. 04, p. 32-40, 2015. DOI: <http://dx.doi.org/10.18677/Agrarian_Academy_015>. Acesso em: 28 abr. 2016.

BRASIL. Ministério da Agricultura, Pecuária e Abastecimento. Defesa Animal. Legislações. Legislação por Assunto. Legislação de Produtos Apícolas e Derivados. Instrução Normativa n. 11, de 20 de outubro de 2000. Regulamento técnico de identidade e qualidade do mel. Disponível em: <http://www.agricultura.gov.br/sda/dipoa/in_11_2000.htm>.

CHAVES, A. F. A.; GOMES, J. E. H.; COSTA, A. J. S. Caracterização físico-química do mel de Melipona fulva Lepeletier, 1836 (Himenoptera: Apidae: Meliponinae) utilizada na meliponicultura por comunidades tradicionais do entorno da cidade de 
Macapá-AP, Biota Amazônica, v. 2, n. 1, p. 1-9, 2012. DOI: <http://dx.doi.org/10.18561/2179-5746/biotaamazonia.v2n1p1-9>. Acesso em: 18 mar. 2016.

CHUTTONG, B.; CHANBANG, Y.; SRINGARM, K.; BURGETT, M. Physicochemical profiles of stingless bee (Apidae: Meliponini) honey from South East Asia (Thailand). Food Chemistry, v. 192, p. 149-155, 2016. DOI: <http://dx.doi.org/10.1016/j.foodchem.2015.06.089>. Acesso em: 23 mar. 2016.

Ciência e Tecnologia de Alimentos, v. 32, n. 3, p. 547-552, 2012. DOI: <:http://dx.doi.org/10.1590/S0101-20612012005000066>. Acesso em: 02 mar. 2016.

DAMASIA-GOMES, L.; FALEIRO, K. M.; SANTOS, S. O.; GUIMARÃES, L. E.; SILVA-NETO, C. M. Physical-chemical characteristics of honey on Brazil. Enciclopédia Biosfera, v. 11, n. 2, p. 570-682, 2015. DOI: <http://dx.doi.org/10.18677/Enciclopedia_Biosfera_2015_110>. Acesso em: 28 abr. 2016.

ESCUREDO, O.; DOBRE, I.; FERNANDEZ-GONZALEZ, N.; SEIJO, M. C. Contribution of botanical origin and sugar composition of honeys on the crystallization phenomenon. Food Chemistry, v. 149, p. 84-90, 2014. DOI: <http://dx.doi.org/10.1016/j.foodchem.2013.10.097> Acesso em: 03 mar. 2016.

IBGE. Instituto Brasileiro de Geografia e Estatística. Ministério do Planejamento, Orçamento e Gestão. Produção da pecuária municipal 2013. Rio de Janeiro, v. 41, p. 1-108, 2013. Disponível em: <hftp://ftp.ibge.gov.br/Producao_Pecuaria/Producao_da_Pecuaria_Municipal/2013/p pm2013.pdf>. Acesso em: 23 fev. 2016.

INSTITUTO, Adolfo Lutz. Métodos físico-químicos para análise de alimentos. 4. ed. São Paulo: Instituto Adolfo Lutz, 1020 p. 2008.

KAMAL, M. A.; KLEIN, P. Determination of sugars in honey by liquid chromatography. Saudi Journal of Biological Sciences, v. 18, p. 17-21, 2011. DOI: <http://dx.doi.org/10.1016/j.sjbs.2010.09.003>. Acesso em: 13 mar. 2016.

LACERDA, J. J. J.; SANTOS, J. S. dos S.; SANTOS, S. A.; RODRIGUES, G. B.; SANTOS, M. L. P. Influência das características físico-químicas e composição nas cores de méis produzidos por Apis mellifera no sudeste da Bahia utilizando análise multivariada. Química Nova, v. 33, n. 5, p. 1022-1026, 2010. Disponível em: <http://www.scielo.br/pdf/qn/v33n5/03.pdf>. Acesso em: 20 jan. 2016.

MOURA, S. G.; MURATORI, M. C. S.; MONTE, A. M.; CARNEIRO, R. M.; SOUZA, D. C.; MOURA, J. Z. Qualidade do mel de Apis mellifera L. relacionadas às boas práticas apícolas. Revista Brasileira de Saúde Produção Animal, v. 15, n. 3, p. 731-739, 2014. Disponível em: <http://www.scielo.br/pdf/rbspa/v15n3/a21v15n3.pdf> Acesso em: 23 mar. 2016.

PONTARA, L. P. M.; CLEMENTE, E.; OLIVEIRA, D. M.; KWIATKOWSKI, A.; ROSA, C. I. L. F.; SAIA, V. E. Physicochemical and microbiological characterization of 
cassava flower honey samples produced by africanized honey bees. Ciência e Tecnologia de Alimentos, v. 32, n. 3, p. 547-552, 2012. DOI: $<$ http://dx.doi.org/10.1590/S0101-20612012005000066. Acesso em: 05 jan. 2016.

PRONI, E. A.; MACIEIRA, O. J. D.; Ritmo circadiano da taxa respiratória de Tetragonisca angustula fiebrigi (Schwarz), T. a. angustula (Latreille) e Trigona spinipes (Fabricius) (Hymenoptera, Apidae, Meliponinae) Revista Brasileira de Zoologia, v. 21 n. 4, p. 987-993, 2004. Disponível em: <http://www.scielo.br/pdf/rbzool/v21n4/22965.pdf> Acesso em: 18 fev. 2016.

QUEIROGA, C. R. M.; LEITE-FILHO, F. G.; MACHADO, A. V.; COSTA, R. O. Cadeia produtiva do mel de abelhas: fonte alternativa de geração de renda para pequenos produtores e qualidade físico-química do mel. Revista Brasileira de Agrotecnologia, v. 5, n. 1, p. 24-30, 2015. Disponível em: <http://www.gvaa.com.br/revista/index.php/REBAGRO/article/view/3681/pdf-10>. Acesso em: 05 fev. 2016.

SILVA, P. M.; GAUCHE, C.; GONZAGA, L. V.; COSTA, A. C. O.; FETT, R. Honey: Chemical composition, stability and authenticity. Food Chemistry, v. 196, p. 309323, 2016. DOI: <http://dx.doi.org/10.1016/j.foodchem.2015.09.051>. Acesso em: 22 jan. 2016.

SILVA, W. P.; PAZ, J. R. L. Abelhas sem ferrão: muito mais do que uma importância econômica. Natureza on Line, v. 10 n. 3, p. 146-152, 2012. Disponível em: <http://www.naturezaonline.com.br>. Acesso em: 23 mar. 2016.

SOHAIMY EI S. A.; MASRY S. H. D.; SHEHATA M. G. Physico chemical characteristics of honey from different origins. Annals of Agricultural Science, v. 60 , n. 2, p. 279-287, 2015. Disponível em: <www.elsevier.com/locate/aoas>. Acesso em: 01 mar. 2016.

SOUZA, R. C.; YUYAMA, L. K. O.; AGUIAR, J. P. L.; OLIVEIRA, F. P. M. Valor nutricional do mel e pólen de abelhas sem ferrão da região amazônica. Acta Amazonica, v. 34, n. 2, p. 333-336. 2004. Disponível em: <http://www.scielo.br/pdf/aa/v34n2/v34n2a20.pdf>. Acesso em: 12 mar. 2016.

VILLAS-BÔAS, J. K.; MALASPINA, O. Parâmetros físico-químicos propostos para controle de qualidade do mel de abelhas indígenas sem ferrão no Brasil. Mensagem Doce, n. 82, p. 6-16, 2005. Disponível em:< http://www.apacame.org.br/mensagemdoce/82/artigo2.htm>. Acesso em: 01 mai. 2016. 